Revista Iberoamericana, Vol. LXXI, Núm. 210, Enero-Marzo 2005, 275-287

\title{
REVISANDO/REVISUALIZANDO GÊNEROS: A NOITE ESCURA E MAIS EU E INVENÇÃO E MEMÓRIA DE LYGIA FAGUNDES TELLES
}

\author{
POR \\ Susan CANTy QuinLan \\ University of Georgia
}

\begin{abstract}
[Mas feminismo é isto,]
feminismo é ter uma finalidade, um objetivo.

Acho que feminismo é exatamente

o trabalho que a mulher dever realizar.

Sua presença deve se fazer sentir

em todos os ramos de atividades,

detestando todo tipo de preconceito

(Fagundes Telles. Entre resistir e identificar-se 63)

Mesmo que os amantes se percam, continuará o amor.

Dylan Thomas "E a Morte Perderá o Seu Domínio”
\end{abstract}

INTRODUÇÃO

O foco de muitos estudos sobre as personagens da escritora brasileira Lygia Fagundes Telles se concentra na relação entre ficção e realidade como pano de fundo nos textos e com a habilidade ou sua falta por parte das mesmas personagens para construírem uma identidade baseada num entendimento ético-moral do eu como sujeito independente dentro de um mundo ambíguo e solitário. Como já colocou a Peggy Sharpe:

Despite the strength and sheer courage of Fagundes Telles's characters, few are able to complete the process of metamorphosis that would free them from their solitude, decadence and lack of identity... (79)

O que Sharpe propõe no seu comentário é mais aplicável nos primeiros romances da Fagundes Telles (tais como Ciranda de pedra [1954], Verão no aquário [1963], e As horas nuas (1989), ${ }^{1}$ mas a trajetória da autora muda de direção a partir dos anos 90 do século passado vindo até o presente. Este processo de estar sempre “se tornando” transforma em

\footnotetext{
${ }^{1}$ As meninas (1973) poderia ser considerada um caso aparte no sentido de que pudesse ser entendida como um romance engajado tratando de época militar. Ver Wasserman, Renata "The Guerilla in theBathtub: As meninas and the Imposition of Modern Politics".
} 
questões de outras maneiras de ver o próprio ato não só de se tornar, mas também de escrever. O que muitos críticos apontam como seu estilo intimista não nos deixa com uma visão de verdade verdadeira conforme a um conhecimento tanto da autora quanto da obra mas sim com uma idéia do que é difícil de ser contado, a do inconsciente. São as características que privilegia Fagundes Telles quando escreve sob o mundo que conhece melhor.

Com a publicação do livro de contos A noite escura e mais eu, em 1995 (reeditado e reescrito em 1999), ${ }^{2}$ e com a publicação do premiado livro Invenção e memória (2000) ${ }^{3}$ temos algumas personagens, por exemplo, o cachorro no conto “O crachá nos dentes”, Maria Leonor em "Boa noite, Maria”, a mãe e a filha em "Uma branca sombra pálida”, o anão em “Anão no jardim”, o ganso e o galo em "Suicídio na granja”, o menino/homen/velhinho em "Se es capaz”, ou o noruguês e a menina em "Potyra” e a própria escritora como personagem em vários contos como "Rua Sabará 400”ou "Heffman” que se metamorfoseiam em atos surpreendentes, as vezes surrealistas, às vezes com um forte tom político, para se autoidentificarem. Podem-se reduzir os atos aqui ao processo autorial de abraçar o conceito da morte ou da moralidade e transformá-los na própria escolha da personagem pelo renascimento. É como se tivéssemos não só o amadurecimento da autora com o amadurecimento do próprio texto.

Podemos anotar algumas diferenças nas duas obras de Fagundes Telles. Em A noite escura e mais eu, por exemplo, vemos uma liberação tanto do tema quanto da problemática do eu na abordagem de outras sexualidades: homossexuais, auto-erotismo, violação e a sexualidade das idosas, por exemplo. Em Invenção e memória, as questões se tornam mais filosóficas, porém mais problemáticas. Os estilos dos dois livros merecem ser destacados tanto pelas diferenças quanto pelas semelhanças. A noite escura e mais eu é um livro de contos que se preocupa mais não só com contar estórias, mas também com a estética do escrever. Usando um estilo renovador, mas coloquial até certo ponto, Fagundes Telles faz de Invenção e memória um livro que mostra sua vasta capacidade de capturar a problemática entre o que sabemos e o que inventamos sobre nossas próprias vidas. Não é surpreendente que o livro tenha atraído um público leitor jovem, embora a autora tenha setenta e sete anos. Talvez o que una os dois livros é a fria liberdade da escritora de escrever o que ela quer. Fagundes Telles mostra com suas personagens a gama de sentimentos que a chamada vida (pós) moderna provoca num mundo que parece ser fora de controle. Uma tensão interiorizada permeia o texto, onde conflitos subjetivos são levados no ritmo da observação e da memória. Fagundes Telles sempre foi considerada uma narradora intimista. Se isto quer dizer que ela escreve com uma sintaxe pessoal e com sua própria linguagem límpida e nervosa, podemos concordar. Muitas vezes, Fagundes Telles evoca cenas e estados de espírito da infância e da adolescência, alguns tristes e amargos, outros impregnados de humor sutil e fina ironia. Mas também nos últimos livros existem uma liberdade sexual e uma postura inquiridora perante à morte. Há, escuridão, solidão e loucura, mas também bastante romantismo, crítica social e, principalmente, esperança.

\footnotetext{
${ }^{2}$ Não nos cabe comparar as diferenças das várias versões de alguns contos aqui. Mas seria interessante fazê-lo no futuro.

${ }^{3} \mathrm{O}$ livro ganho o Prémio Jabuti no ano 2000 como o melhor livro do ano.
} 
Para entender melhor o novo processo de Fagundes Telles, é interessante e útil considerarmos alguns conceitos definidos por Marjorie Garber. Penso claramente nos termos de Garber, quando ela fala de uma terceira maneira de ver o processo da formação de identidade do eu (seja feminina, masculina, ou queer): o processo de "cross-dressing” (travestismo), que é outro indicador de um processo literário que procura encontrar as ligações entre moralidade, sexualidade e textualidade. Aqui proponho também que podemos colocar a idéia da terceira idade, o seja, o encontro com a morte iminente.

No seu livro Vested Interests, Garber introduz a idéia de 'uma categoria em crise,' ou seja, "a failure of definitional distinctions, a borderline that becomes permeable, that permits border crossings from one category (apparently distinct) to another” (916). Como é que podemos identificar esta zona fronteiriça permeável? Para Garber é o travestismo, e a localização do travestismo significa mais do que "cross-dressing”:

Tranvestism is a space of possibility, structuring and confounding culture: the disruptive element that intervenes, not just a category crisis of male and female, but a crisis of category itself. (17)

Qual poderia ser a ligação entre cultura literária e popular tanto numa literatura quanto numa cultura que promove a entrada de um terceiro modo de aprender e compreender idade, sexualidade, sexo e gênero numa análise de literatura? Para Garber é uma outra via, “'third’, a mode of articulation, a way of describing a space of possibility. Three puts in question the idea of one: of identity, self-sufficiency, self-knowledge”(11). Num contexto especificamente brasileiro, como aponta Dan Kulick, as protagonistas ou travestis são concentrações de idéias gerais, representações da praxis de ser masculino e feminino (ou da tarefa quotidiana de se assumir uma sexualidade) que elaboram configurações particulares de sexualidade, gênero e sexo e que sublinham e definem as noções brasileiras de ‘homem' e 'mulher'. De modo geral, o travestismo brasileiro quebra as definições binárias de sexo e sexualidade na mesma maneira que Oswald de Andrade conclamara os escritores modernistas a devorar outras culturas e literaturas para assumir uma brasilidade. Para ir mais além de Garber, a capa de sexualidade no caso telliano poderia ser notada no próprio ato de assumir não só a sexualiade, mas também a mortalidade. Em outras palavras seria a mistura de sexualidade e terceira idade.

Em Fagundes Telles, que sempre trabalha nas margens entre a realidade e o imaginário, tanto com as protagonistas em geral quanto com outras visões de sexualidade em particular, certos contos da coleção de A noite escura e mais eu e Invenção e memória mostram claramente uma liberação de definições binárias e indicam que, nas palavras de Severo Sarduy:

The very fact of transvestism itself... [T]he co-existence of masculine and feminine signifiers in a single body, the tension, the repulsion, the antagonism created between them (37)

são fundamentais ao processo de escrever.

A questão é: como trabalhar com as identidades que são e não são pessoais? Como transcrever os lugares de tais identidades numa maneira em que elas sejam entendidas e 
entendam ao mesmo tempo? A tarefa autoral de suma importância é traduzir diferenças, como Sarduy aponta:

Those places of intersexuality are analogous to the planes of intertextuality that make up the literary object. They are planes conversing in the same exterior, answering and completing, exalting and defining each other: that interaction of linguistic textures, of discourses, that dance, that parody, is writing. (37)

O ato de misturar intersexualidade com intertextualidade reflete e redefine o dilema na problemática de definir uma cultura brasileira a partir de uma ótica de mulher. Cristina Ferreira-Pinto é muito clara ao referir-se à importância do lugar de Fagundes Telles neste quadro, quando abre mão do reconhecimento de que a mulher brasileira “é na verdade várias mulheres” (70). Ferreira-Pinto continua falando da literatura brasileira de mulher em geral e logo especificamente de Fagundes Telles, dizendo:

É possível afirmar que a obra de ficção de nossas escritoras tem sido instrumental em criar uma consciência feminista junto a suas leitoras, ainda que se repudie o feminismo como rótulo. (67)

Central na obra de Lygia Fagundes Telles desde o início de sua carreira de escritora, a questão de identidade feminina tem sido enfocada sobre um eixo principal constitutivo dessa identidade, que é o das relações entre mulheres, além, é claro, do aspecto mais óbvio que é o das relações homem-mulher. (69)

Para Fagundes Telles, escrever é criar pontes entre as personagens e também entre fatos para construir suas vidas, juntando palavras e imagens que compõem sua verdade inventada. Os temas comuns entre os dois livros são ligados com os de morte, velhice, solidão, medo e angústias.As diferenças mais destacáveis seriam a nítida inclusão de sexualidade aberta em A Noite e a plena preocupação com ambigüidade e morte em Invenção. Pretendo analisar alguns contos de cada livro para ver as ligações entre eles.

A NOITE ESCURA E MAIS EU

Esta coleção de nove contos foi publicada em 1996 e reeditada e republicada em 2000. A solidão poderia ser o pano de fundo que permeia o livro que traz enredos ambíguos e cujo título nasceu de um poema de Cecília Meireles.

“Uma branca sombra pálida”

Em “Uma branca sombra pálida”, uma nova versão do conto “A escolha”, ${ }^{4}$ a relação familiar entre a mãe e a filha, e a amante da filha existe dentro de uma zona ambígua, possibilitando a existência de várias categorias em crise. Podemos destacar a relação fria da mãe que não gosta de ser tocada e que sempre mantém imagens infantis da filha ou o

${ }^{4}$ Publicada em Histórias de amor infeliz (129-33). 
emocional namoro lésbico da filha, combatente em certos aspectos ou finalmente a (não) relação entre a mãe e a amante.

A narradora, a mãe de Gina, introduz a problemática desde o início, quando fala do suicídio da filha lésbica:

Gina ficou com suas narinas livres para voltar a respirar se quisesse. Não quis. Está certo, foi feita a sua vontade. Ela era voluntariosa, quando resolvia uma coisa, hein? (162 grifos meus)

Mas por quê o suicídio? Temos só as reflexões da mãe em frente do túmulo e suas revelações do processo de pensamento da ex-bailarina Gina:

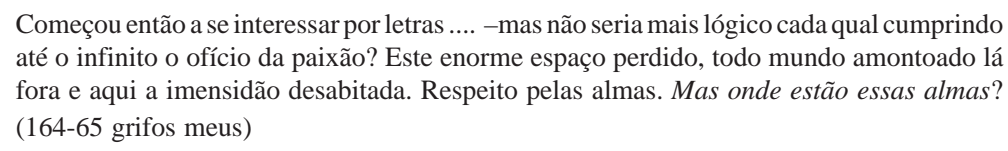
até o infinito o ofício da paixão? Este enorme espaço perdido, todo mundo amontoado lá fora e aqui a imensidão desabitada. Respeito pelas almas. Mas onde estão essas almas? (164-65 grifos meus)

E mais adiante:

A morte é um sopro, ouvi a pequena Gina dizer ao Pai... A alma, a tal essência sutil, só ela continua imperecível. Imperecível e consciente (168).

Sabemos que a jovem optou pela morte como o único ato que permitisse visar à outra a via, a "terceira” ou a categoria em crise. Para assimilar sua identidade lésbica, ou seja, renascer, Gina precisava tomar sua própria decisão, dada a impossibilidade de aceitar as condições de vida oferecidas pela mãe: a mãe ou a amante. Para Fagundes Telles, a morte como veremos mais adiante, não significa um final, mas sim, uma entrada na fronteira permeável.

\section{“O Anão”}

Retomando a figura do anão, que apareceu pela primeira vez no romance, Ciranda de Pedra (1954), Fagundes Telles recria o lugar da alma, que fez parte da busca de Gina. Quando o anão fala da derrubada da estátua que está por perto, explora mais detalhadamente o conceito da alma, lugar obviamente sem gênero binário:

É com arrogância que agora espera a morte? Não tenho medo ... e essa é outra diferença importante entre um anão de pedra e um homem, a carne é que sofre o temor e tremor mas meu corpo é insensível, sensível é esta habitante que se chama alma... [S]ei apenas que esta alma vai continuar não mais neste corpo rachado mas em algum outro corpo que Deus vai me destinar. (194)

Referindo-se ao processo de reincarnação, Fagundes Telles nos indica o processo de renascer, de poder entender melhor a ligação entre corpo e mente. Isto é, a possibilidade de permear esta zona fronteiriça, esta 'terceira categoria”. A alma é o lugar onde coexistem o 
masculino e o feminino. Discordo com a orelha do livro que indica que o conto "Fala de uma perseguição à imortalidade, de uma continuação da vida em qualquer forma, mesmo a mais vil” (http://www.editoras.com/rocco/022079.htm). Discordo porque o anão já sabe que vai renascer na forma certa, qualquer que seja:

Pai nosso que estais no céu com a Constelação do Escorpião brilhando gloriosa brilhando com todas as suas estrelas e o braço do homem se levanta e fecho os olhos Seja feita a Vossa vontade e agora a picareta e então aceito também ser a estrela menor da grande cauda levantada no infinito no infinito deste céu de outu/bro. (202)

O anão sabe que a perspectiva do eu que terá na vida nova seria mais verídica.

“O crachá nos dentes”

É muito comum na literatura de Fagundes Telles encontrarmos animais ou, às vezes, objetos humanizados. É só lembrarmos do gato narrador no romance As horas nuas (1989) que tem muito a ver com o anão do conto já referido. Os dois davam voz às perplexidades e indignações num entendimento das ações dos seres humanos no mundo. Lembramo-nos também da borboleta com as suas perguntas agudas no conto “Uma branca rosa pálida,"que antecipa o começo do processo de auto-reflexão por parte da mãe no túmulo da filha. Todas estas figuras são 'cross-dressers,' travestis, no sentido que permitem uma leitura do eu a partir de uma nova ótica. Obviamente questionam completamente a identidade do eu e refletem as definições de atos morais e éticos.

Mas é no conto mais curto da antologia, “O crachá nos dentes,”que Fagundes Telles demonstra a força deste animal, ao comentar a violência do dia-a-dia do ser humano. O conto em si é uma metáfora para uma sociedade alienada e cheia de problemas, sem resolução.

Para entender melhor, cito o primeiro parágrafo:

Começo por me identificar, eu sou um cachorro. Que não vai responder a nenhuma pergunta, mesmo porque não sei as respostas, sou um cachorro e basta. Tantas raças vieram em desaguar em mim como os afluentes de pequenos rios se perdendo e se encontrando no tempo e no acaso, mas qual dessas raças acabou por vigorar na soma. Isto eu não sei dizer. Melhor assim. Fico na superfície sem indagar da raiz, agora não. Aqui onde estou posso passar quase despercebido em meio de outros que também levam os crachás dependurados no pescoço como os rótulos das garrafas de uísque. Que ninguém lê com atenção, estão todos muito ocupados para se interessar de verdade por um próximo que é o único e múltiplo apesar da identidade. (65)

O cachorro fala também da inabilidade de fazer relações íntimas e permanentes com os outros. Enfatiza isto, embora sutilmente, quando fala de abuso físico por parte do treinador do circo, que queima as patas/os dedos com a ponta de cigarro. Fala também do processo de metamorfose, quando se apaixona por um ser humano e vira "um mutante” sem medo quando se descobriu “em liberdade”. Mas quando disfarçou o amor, virou cachorro de novo, voltando ao circo. Depois de uma escolha consciente pode localizar o eu, mas este eu fica sumamente dependente dos outros. O final do conto mostra claramente que o desejo 
de se identificar não é suficiente, mas sim dá para perceber a visão da "terceira categoria” no pleno ato de "cross-dressing".

\begin{abstract}
Dei valor aos meus dedos só depois que os perdi... Com aqueles dedos toquei flauta mas nunca me masturbei, nunca me masturbei enquanto fui um ser humano, não é estranho isso? Há ainda outras estranhezas, não importa. Aprendi também a rezar. Gosto muito de ouvir música e de ficar olhando as nuvens. Mas sou um cachorro e quando alguém duvida, mostro as palmas das minhas patas queimadas. (68-9)
\end{abstract}

"Boa Noite Maria”

“Boa noite, Maria” é talvez o conto mais famoso da coleção por causa do conteúdo chocante, mas interessante e talvez o mais atual. A problemática do conto enfoca o que podemos destacar como o novo rumo das mulheres da geração que surge depois da segunda guerra mundial e das mulheres que pertencem a geração dos baby boomers, ou seja, da segunda onda de feminismo. São elas as que aprenderam escrever sobre sua própria realidade como processo de entendimento ou identificação do eu e que continuam fazendoo. Indica-nos aqui que a busca da identidade não pode ser completada uma vez para sempre. Está sempre em transição Telles mostra de novo que a 'categoria em crise' ou seja a busca do lugar do eu num contexto de uma cultura, uma sociedade nunca pode ser resolvida porque depende sempre nos momentos específicos das vidas.

Aqui, Fagundes Telles fala dum processo feminil de envelhecer que pertence à classe média e alta brasileira. Fala também do desejo e do prazer sexual das mulheres idosas e, mais importante, fala da possibilidade de eutanásia. O tema central é a solidão frente à morte e a necessidade da protagonista, Maria Leonor, de escolher seu próprio momento de morrer.

O conto é divido em duas partes: a primeira é um encontro qualquer no aeroporto entre uma velhinha de sessenta e cinco anos e um homem, Julius, na faixa dos cinqüenta anos. ${ }^{5}$ Como leitores, temos que aceitar o encontro como uma coisa já marcada numa outra realidade. É aqui também onde a protagonista começa a ruminar sobre as "refrescadas" feitas por causa das relações amorosas e as efêmeras durações delas. É a necessidade de refazer o eu físico. Contém, ao mesmo tempo, uma definitiva resolução para o final da vida dela.

E a morrer quando chegasse a hora de morrer. Uma morte sem humilhação e sem dor. A morte respeitosa -mas era pedir muito? Precisava de um amigo e não de um assassino... Tamanho horror pelas doenças aviltantes que deixam a boca torta e o olho vidrado. E a fralda, Ah! Senhor, a fralda não!

O amigo tem que amar esse próximo como a si mesmo, se ainda é possível o amor. Permitir que esse próximo amado fique indefinidamente num estado miserável não é cruel? E a compaixão? Seria um simples gesto de compaixão, a morte por compaixão. (90)

${ }^{5}$ Uma situação que nos lembra do filme Harold and Maude. 
Depois vem uma discussão ética da eutanásia, onde a autora expõe os problemas morais de um ato criminoso: “Não, a eutanásia não é crime se nasce de um pacto, de um acordo entre as partes” (92).

A segunda parte do conto, supostamente após um ano, conta o último dia da vida de Maria Leonor, quando Julius finge que é um recomeço; ele mostra as passagens para fazer um cruzeiro no futuro, enquanto ele bota o 'remédio' num copo de vinho. O final é tipicamente ambíguo, como acontece nos outros contos da coleção:

Segura minha mão, quero sua mão, ah; como é bom, Julius querido, fica aí e escuta... Julius querido, querido é uma coisa tão importante, mas tão importante. .Está me ouvindo? Com você eu voltei à infância, sabe o que é voltar à infância? Estou aqui caindo de sono e resistindo como resistia no colo da minha mãe, está me ouvindo?... Eu ficava no colo da minha mãe e não queria dormir, não queria! (101)

Aqui temos uma tentativa de parar o ato de eutanásia? Ou é simplesmente o ato de abraçar a morte, comparando-a com o período mais perfeito na vida da Maria Leonor?

INVENÇÃO E MEMÓRIA

Lygia Fagundes Telles sempre se renova e nos surpreende com sua imaginação prodigiosa, sua linguagem altamente elaborada -que, mesmo assim, brinca o tempo todo com o leitor-e seu riquíssimo universo ficcional. O que é surpreendente para muitos leitores é o fato de, aos setenta e sete anos, Fagundes Telles ter capturado uma nova faixa de leitores novos e jovens com a publicação deste livro de quinze contos. Invenção e memória ganhou o Prêmio Jabuti como o melhor livro do Brasil na categoria ficção da Bienal do Livro de 2000. Existem muitos destes temas em A noite escura e mais eu, só que aqui tem muito mais a ver com a vida pessoal da autora (as memórias) e o ser humano frente à sua história (as invenções). A demarcação entre os sois conceitos funcionariam assim, se na verdade poderiamos distinguir emtre eles. É uma tarefa impossível porque as fronteiras de invenção e memória são entrelaçadas.

"Suicídio na granja”

Em “Suicídio na granja”, há o encontro da infância (o alvorecer da vida) com a morte -esse tema que é onipresente nas obras de Fagundes Telles. A narradora/escritora se mostra primeiro numa adolescência de sonhos e fantasias que a autora trata com humor negro ao representá-la mais velha. Fagundes Telles se transforma em locutora para disfarçar mais uma vez a realidade e confundir invenção com memória.

A primeira parte do conto se abre com uma menina falando com o seu pai sobre o suicídio de um conhecido que encheu os bolsos com pedras e se afundou num rio. O conto não consta só da menina, conversando com seu pai sobre o que é suícídio, mas também de perguntas sérias sobre vida e morte. "Suicídio por justa causa e sem causa alguma e aí estaria o que podemos chamar de vocação... Muitos se matam por amor mesmo. Mas outros motivos, tantos motivos... (17-18). Logo depois a menina pergunta ao pai: 
Quem se mata vai pro inferno, pai? Ele apagou o charuto no cinzeiro e voltou-se para me dar o pirulito que eu tinha esquecido em cima da mesa. O gesto me animou, avancei mais confiante: e bicho, bicho também se mata? Tirando o lenço do bolso ele limpou devagar as pontas do dedo: Bicho, Não, só gente. (19)

Surpreendente aqui é o conteúdo violento embora a autora use uma linguagem até brincalhona e o espaço nos lembre uma cena pastoril.

A segunda parte do conto “muitos e muitos anos depois” se concentra na relação de dois animais. As personagens, um ganso chamado Platão e um galo chamado Aristóteles são os melhores amigos que fazem tudo juntos. A personificação dos animais não se compara com o cachorro que narra o conto "Um crachá nos dentes”, porém a intenção parece ser semelhante. Serve para fazer um comentário crítico-ético.

Na adolescência a narradora visita uma fazenda e anota suas observações:

... Nessa granja encontrei dois amigos inseparáveis... Uma estranhíssima amizade...dois amigos tão próximos, tão apaixonados, ah como conversavam em seus longos passeios, como se entendiam na secreta linguagem de perguntas e respostas, o diálogo. (19)

Os dois bichos ${ }^{6}$ pertencem um ao outro até o momento da matança acidental do ganso para ser servido num grande jantar. O galo fica preso a sua agonia de perder o amigo e começa procurar incessantemente o outro em vão.

No final do conto a adolescente/mulher recusa voltar à cena pastoril onde dever ter encontrado toda a paz e tranqüilidade do mundo.

Deixei de ir à granja, era insuportável ver aquele galo definhando na busca obstinada, a crista murcha, o olhar esvaziado. E o bico, aquele bico tão tagarela agora pálido, cerrado. Mais alguns dias e foi encontrado morto ao lado do tanque onde o companheiro costumava se banhar. No livro do poeta Maiakóvski (matou-se com um tiro) há um verso que serve de epitáfio pra o galo branco: comigo viu-se doida a anatomia / sou todo um coração! (21)

Suicidar-se por amor é obviamente uma possibilidade e a referêcia a Maiakovsky, de repente, anula a visão bucólica da estória.

"Potyra"

Potyra é a estória mais longa e mais complicada do livro. Pode-se ser lida em vários níveis: históricos / alegóricos, como um conto gótico, com ênfase no religioso ou em um nível psicológico. Mas, na verdade, o conto tem que ser lido em todos os níveis.

O enredo é bastante simples. Uma menina à espera do pai no Jardim de Luzes no pôrdo-sol encontra uma figura estranha que começa de adivinhar os seus pensamentos. E segue uma longa conversa, ou não, até o amanhecer, quando parece que a figura estranha morre

\footnotetext{
${ }^{6}$ Vale a pena notar que a palavra bicho lembra no bicha que é um termo comum significando um homosexual. A relação entre os dos machos, o ganso e o galo, poder ser lida como metafora.
} 
desaparecendo. Só que o protagonista admite que a forma humana que possui é uma aparência “onde desenvolve uma certa química” (104).

Talvez seja interessante lembrar que Invenção e memória foi publicado em 2000 quando o Brasil celebrou seu quinto centenário e houve muitos protestos contra a exclusão dos índios, os brasileiros nativos. O protagonista central é um norueguês chamado Ars Jacobsen e Potyra é o nome da amada índia que morreu. As referências aqui sugerem uma ligação provocativa com os romances indianistas do José de Alencar O guarani (1857) e Iracema (1865).

Por outro lado é uma história de guerra baseada na colonização da América Latina pelos europeus com a forte doutrinação da igreja católica. Fala do genocídio dos primeiros habitantes do Brasil. Para enfocar a linha delicada entre realidade e ficção podemos comparar duas citações do texto. No primeiro, Fagundes Telles usa livremente a Carta de Pedro Vaz de Caminha quando descreve Potyra;

\begin{abstract}
Uma graciosa tanga de penas coloridas cobria seu sexo de menina mas os pequeninos seios desabrochavam livres sob os fartos colares de continhas azuis. Por entre os colares, um fio mais longo com cruz de estanho, era catequizada, os religiosos que por ali já tinham passado plantaram a Cruz de Cristo e fizeram as advertências, as vergonhas deviam ficar escondidas. $(109-10)$
\end{abstract}

E no segundo, após da morte violenta de Potyra, Ars constata que "A verdade é que os bons colonizadores estavam se esmerando nos processos do extermínio da raça” (114).

Em um nível, o conto nos lembra os mitos de vampiros que se alimentam do sangue ou dos pensamentos dos outros. "Nas minhas caminhadas, seduzi um curumim desgarrado, sorvi algumas gotas do seu sangue...” (111) ou “[Eu sou ] Só uma mentira que vai acabar nesta madrugada...” (104).

No transcorrer do conto, há bastantes referências à homossexualidade, hermafroditismo e heterossexualidade. Quando a narrativa entra no plano das sexualidades, Ars quase sempre evoca a deusa grega, Ananke, aquela que nasceu de si mesma e seus braços entrelaçaram o universo. Ela é a matéria-prima. O nome romano é Necessitas, o de que precisamos. Ananke com seu esposo, Khronos, são os primeiros seres no começo dd tempo. Ananke aqui simboliza a força do destino que permite que Ars seja liberado na "liberação de um morto que agora vai viver na morte, aleluia!” (115).

Embora tenhamos apenas uma pequena amostra de como ler este texto, a justaposição entre uma realidade quase mágica e os elementos surrealistas demonstra uma flexibilidade da narrativa que é magnífica.

"Se es capaz"

Este conto toma o nome do famoso poema do poeta inglês, Rudyard Kipling, "If". Embora o poeta seja considerado um pouco fascista, o poema recorre à Bíblia no sentido de que a Bíblia que oferece um estilo de boa conduta. O poema é dado como presente por um velho avô para seu neto adolescente. 
O adolescente fixou com tachas na parede do quarto o poema Se..., de Rudyard Kipling, presente do avô. Releu emocionado o pergaminho com as vistosas letras góticas em vermelho e negro e lembrou das palavras do velho: Quero que guarde esta carta de princípios para sempre. (31)

O poema serve como uma maneira de reflexão durante a vida do adolescente até envelhecer. Às vezes o protagonista tenta seguir os princípios, às vezes ele vai completamente além das supostas indicações. Mas o que existe dentro do conto é uma fria tristeza e uma vida vazia. Podemos ver a alegria do protagonista como menino querendo ser bombeiro transformar na banalidade de uma pessoa que só quer enriquecer. Podemos ver três casamentos ‘cansativos' e um filho vagabundo. Os detalhes desta vida quase monótona são repugnantes. A simpatia que começou o livro desce até o ódio. Ao envelhecer, o protagonista chega a ter tido uma vida sem nenhum aspeto de auto-conhecimento e uma grande falta de esperança.

Aposentou-se (a horda feroz das novas gerações) e vendeu o último imóvel que lhe restara, estava pobre. O filho jogador, arruinado. Todo dolorido (artrite), foi morar num modesto apartamento com um jovem acompanhante. E que me odeia. (35)

Como idoso, o protagonista reverte o poema da adolescência para tentar repensar a vida. Só que ele não pode perder sua visão amarga dos outros. É como se o poema fosse escrito numa linguagem desconhecida. Nesta contrição de atos incompletos que talvez explicassem o porquê da sua vida, o velho não pode negar sua própria personalidade.

Detinha-se às vezes, no velho pergaminho todo comido de traças e fixado com durex na tosca estante no lado da cama, Se...Quase todas as pessoas falavam com alegria na infância e a minha infância? Tirante alguns momentos doces, tudo tinha sido tão cruel. Tão injusto, tantos desentendimentos na família e sempre em voz alta, alta demais... A discórdia. Que prosseguiu (com maior ou menor intensidade) pela vida afora, quando foi enganado e enganou. Aquela desesperada luta pelo poder e no poder a corrupção. A mentira. Uma dúvida, foi no poder que me perdi ou já estava perdido? (36)

A vida do protagonista e o conto terminam com um final banal negando o último desejo do velhinho que quer entrar num convento para se preparar para contemplar a eternidade e morrer. Volta o filho, que está bem financeiramente e interna o pai em uma clínica com uma ala especial para esclerosados.

... clínica de repouso nada deprimente, ao contrário: às quartas tinha ginástica e aos sábados os velhinhos podiam participar de uma esfuziante festa-baile. (38)

“Se es capaz” comenta pelo menos duas realidades: a de uma pessoa da classe médiaalta gastar a vida sem deixar uma marca boa e a do novo tratamento de envelhecer. Nenhuma das possibilidades é boa e ambas refletem a idéia de crise da categoria no final da vida. 
PARa Concluir

Poderia ter falado de outros contos de A noite escura e mais eu. "Dolly", que recria o escândalo de uma jovem atriz e Fatty Arbuckle num espaço brasileiro nos anos 20; ou "O segredo”, que conta a história de um encontro de uma menina e duas decadentes prostitutas velhas no fim das suas carreiras; ou "A rosa verde”,que fala de uma menina que pode matar bichos sem sentimentos; ou os últimos, "Papoulas em feltro negro" e "Você não acha que esfriou?”, porque todos são outras vias para abordar a construção do eu, para encontrar uma identidade, não em linhas retas. Pois um ser humano não é completamente ou isto ou aquilo, ou masculino ou feminino. Nem as próprias mulheres são completamente heterossexuais ou homossexuais. O eu é a reflexão de uma categoria em crise, e como um travesti, veste muitas roupas. E estas roupas, ou seja, performances na língua crítica, combinam-se para definir o eu como parte das culturas ou das sociedades onde vive. Tudo é uma zona fronteiriça permeável.

De Invenção e memória vale destacar os contos que supostamente marcam as memórias de Fagundes Telles. "Rua Sabará, 400”, onde a escritora faz uma citação de Machado de Assis, lembrando Dom Casmurro. Num lugar certo, Fagundes Telles pretende responder definitivamente a culpabilidade ou inocência da figura de Capitu.; ou "Heffman” que parece ser nada mais que uma bem-humorada lembrança de pessoas reais dos tempos de estudante; ou "O Cristo da Bahia”, “Dia de dizer não” e "O menino e o velho”, pungentes crônicas sociais que falam de morte, desesperança e violência.

Em vez de abrir os livros, o trechos de um poema de Cecília Meireles ge um comentário de Paulo Emílio Salles Gomes devem fechá-los. Por enquanto eu fecho com eles:

De A noite escura e mais eu:

Ninguém abra a sua porta

Para ver o que aconteceu:

Saímos de braço dado

De Invenção e memória:

Invento, mas invento

com a secreta esperança

de estar inventando certo.

E digo que Lygia Fagundes Telles está vendo o que acontece.

Bibliografía

Butler, Judith. Bodies That Matter: On the Discursive Limits of Sex. London/New York: Routledge, 1993.

Fagundes Telles, Lygia. Histórias de amor infeliz. Org. Esdras do Nascimento. Rio de Janeiro: Nórdica, 1985.

“A mulher escritora e o feminismo no Brasil”. Entre Resistir e Identificar-se. Peggy

Sharpe, ed. Florianópolis: Editora Mulher/Goiânia: Ed. Da UFG, 1997. 57-65.

Invenção e memória. Rio de Janeiro: Rocco, 2000. 
A noite escura e mais eu. Rio de Janeiro: Rocco, 2000.

Ferreira-Pinto, Cristina. “Consciência feminista/indentidade feminina: relações entre mulheres na obra de Lygia Fagundes Fagundes Telles”. Entre Resistir e Identificar-se. Peggy Sharpe, ed. Florianópolis: Editora Mulher/Goiânia: Ed. Da UFG, 1997. 65-79.

Garber, Marjorie. Vested Interests: Cross-Dressing and Cultural Anxiety. New York/ London: Routledge, 1992.

Kulick, Don. Travesti: Sex, Gender, and Culture among Brazilian Transgendered Prostitutes. Chicago: University of Chicago Press, 1998.

Sarduy, Severo. "Writing/Transvestism”. Written on a Body. Carol Maier, trad. New York: Lumen Books, 1989.

Sharpe, Peggy. "Fragmented Identities and Metamorphosis in Works by Lygia Fagundes Fagundes Telles”. International Women's Writing: New Landscapes of Identity. Anne E. Brown y Marjane E. Goozé, eds. Westport CT: Greenwood Press, 1995. 79-85.

Wasserman, Renata. "The Guerilla in the Bathtub: As meninas and the Imposition of Modern Politics”. Modern Language Studies 19/1 (Winter, 1989): 50-65. 